\title{
Latent Human Herpesvirus - 8 (HHV-8) Infection in Female Commercial Sex Workers From Imbituba, Santa Catarina, Brazil
}

\begin{abstract}
Adele Caterino-de-Araujo ${ }^{1}$, Elizabeth Santos-Fortuna ${ }^{1}$, Mariana Cavalheiro Magri ${ }^{1}$, Fabiana Schuelter-Trevisol ${ }^{2}$ and Marcos Vinicius Silva $^{2,3}$ ${ }^{1}$ Immunology Department, Adolfo Lutz Institute, São Paulo, SP; ${ }^{2}$ University of South of Santa Catarina, Tubarão, Santa Catarina ${ }^{2}$; Emílio Ribas Institute, São Paulo, SP, Brazil
\end{abstract}

\begin{abstract}
Human herpesvirus 8 (HHV-8) infection was identified in 6 out of 90 (6.7\%) female commercial sex workers from Imbituba, Santa Catarina, and was associated to age. Frequencies of $5.6 \%$ of anti-latent and $3.3 \%$ of anti-lytic antibodies were detected. Considering non-endemic areas from Brazil, the anti-latent antibodies frequency seems elevated and requires further investigation on referent female population.

Key-Words: HHV-8, serology, anti-latent antibodies, female sex workers.
\end{abstract}

Infection by human herpesvirus 8 (HHV-8) appears restricted to selected populations in the West, around the Mediterranean but is widespread in many sub-Saharan countries [1]. Studies regarding its presence in Brazil disclosed HHV-8 endemic populations among Amerindians and homosexual/bisexual men infected with HIV-1 [2-8].

HHV-8 is a recently identified virus, which is etiologically associated with Kaposi's sarcoma (KS) [9], and KS has being considered an AIDS-defining illness.

Although the number of KS-AIDS cases were lower in females than in males, studies previously conducted in Europe and the United States showed the highest KS proportions in heterosexual women who reported sexual intercourse with bisexual men (6.9\% and $2.6 \%$, respectively), and who come from African or Caribbean countries (6.8\% and 3.6\%, respectively) [10-11]. The difference emerged from Europe and USA suggests a degree of overlap between the epidemiology of non-AIDS related KS, a very common neoplasm in some of European countries, and among individuals of African or Caribbean origin living elsewhere.

In Brazil, we disclosed frequencies of $7.4 \%$ and $8.6 \%$ of HHV-8 antibodies among HIV-1-infected women from São Paulo city, and pointed the "sexual route" (area where sex commerce is more intense) as the major one for HHV-8 transmission/acquisition [12]. Although these prevalence rates are dramatically lower than the one reported for HIV/AIDS homosexual/bisexual men from the same city (7.4-8.6\% versus 30.4-34\%, respectively) [3-4], and from San Francisco Bay Area ( $4.0 \%$ versus $30-35 \%$, respectively) [13], other studies conducted in Africa, confirmed high HHV-8 seroprevalences in female mostly in commercial sex workers (CSW). For

Received on 26 June 2006; revised 23 December 2006.

Address for correspondence: Dr. Adele Caterino-de-Araujo. Instituto Adolfo Lutz, Seção de Imunologia. Av. Dr. Arnaldo, 355, $11^{\circ}$ andar, Zip code: 01246-902, São Paulo, SP, Brasil. Phone/fax: 55-11-30682898. E-mail: caterino@ial.sp.gov.br

Support: This work was supported by Fundação de Amparo à Pesquisa de São Paulo (FAPESP) grants \# 98/13313-5. The study was reviewed and approved by the Ethical Committee of the Universidade do Sul de Santa Catarina.

The Brazilian Journal of Infectious Diseases

2007;11(1):9-11. (C) 2007 by The Brazilian Journal of Infectious Diseases and Contexto Publishing. All rights reserved. instance, in Cameroon, Central Africa, high prevalence of HHV8 was detected in HIV positive female CSW (51.3\%) when compared to HIV negative pregnant women (36.6\%) [14]. Other studies among prostitutes in Africa disclosed HHV-8 seroprevalences of $44 \%$ in Mombasa, Kenya, and of $8 \%$ in Eritrea $[1,15]$.

\section{Materials and Methods}

In order to add some information concerning HHV-8 seroprevalence in female CSW from Brazil, we conducted the present study. CSW from Imbituba, a port city in Santa Catarina, Southern Brazil, were invited to participate in a seroepidemiological study of sexually transmitted diseases (STDs), including HIV, and HHV-8 [16]. From December, 2003, to February, 2004, 90 prostitutes were interviewed and agreed to participate on the study. Signed informed consents were obtained after answering a questionnaire regarding demographic, socio-economic and behavior variables, and serum samples were collected for serological analysis. HHV-8 antibodies were detected using in-house immunofluorescence and Western blot assays based on BCBL-1 cell line that detected anti-latent and anti-lytic antibodies, as previously described [12]. These assays showed sensitivities of 75-91\%, and specificities of 99-99.7\%, respectively, in studies performed on Brazilian populations [12].

The socio-economic status of each individual was based on Critério Brasil [17], that considers very poor people, classes $\mathrm{D}$ and $\mathrm{E}$, whose income is under $\mathrm{U} \$ 150.00$ per month.

\section{Results}

Using these approaches, the results obtained disclosed an overall HHV-8 antibody frequency of 6.7\% (5.6\% of antilatent and $3.3 \%$ of anti-lytic antibodies). Although this frequency seems very similar to the HHV-8 antibody frequencies detected among HIV/AIDS women from São Paulo, they differ according to HHV-8 latent infection: while HIV/ AIDS patients presented very low frequencies of anti-latent antibodies (0-1.2\%), female CSW showed an increased frequency of $5.6 \%$ (Table 1). Also, if we compare these results with the results obtained in normal healthy women from São Paulo, the HHV-8 anti-latent antibodies continue elevated in prostitutes (5.6\% versus $1.3 \%$ ) (Table 1 ). 
Table 1. Comparative frequency rates of HHV-8 anti-latent and anti-lytic antibodies among female commercial sex workers (CSW) from Imbituba, Santa Catarina, and HIV/AIDS patients and normal healthy women from São Paulo, SP, Brazil

\begin{tabular}{|c|c|c|c|c|c|c|c|}
\hline \multirow{2}{*}{ Group } & \multicolumn{3}{|c|}{ IFA and WB LANA } & \multicolumn{2}{|c|}{ IFA-Lytic } & \multicolumn{2}{|c|}{ HHV-8 antibodies ${ }^{\mathrm{a}}$} \\
\hline & $\mathbf{N}$ & $\mathbf{N}$ & $\%$ & $\mathbf{N}$ & $\%$ & $\mathbf{N}$ & $\%$ \\
\hline Female HIV/AIDS - SP [12] & 163 & 2 & 1.2 & 13 & 8 & 14 & 8.6 \\
\hline Female HIV/AIDS - SP [12] & 108 & 0 & - & 8 & 7.4 & 8 & 7.4 \\
\hline Female Normal Healthy -SP [12] & 630 & 7 & 1.3 & 2 & 0.3 & 8 & 1.5 \\
\hline Homo/Bise Male HIV/ AIDS - SP [3] & 23 & - & - & - & - & 7 & 30.4 \\
\hline Homo/Bise Male HIV/ AIDS - SP [4] & $129^{b}$ & - & - & - & - & 44 & 34.1 \\
\hline Female CSW-SC & 90 & 5 & 5.6 & 3 & 3.3 & 6 & 6.7 \\
\hline Female CSW HIV/AIDS - SC & $6^{c}$ & 1 & 16.7 & 0 & - & 1 & 16.7 \\
\hline
\end{tabular}

a Overall frequency of HHV-8 antibodies according to the group analyzed. Sex risk: homo (homosexual), bise (bisexual), CSW (commercial sex

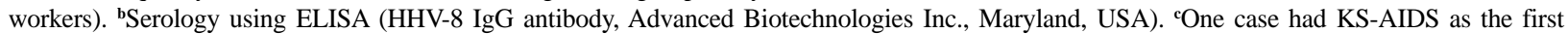
illness and resulted at present, HHV-8-seronegative. [Ref. No] Related to the number of the previous work disclosed in the References session.

Table 2. Characteristics and individual results obtained using HHV-8 serology to detect anti-latent and anti-lytic antibodies in female commercial sex workers from Imbituba, Santa Catarina, Brazil

\begin{tabular}{ccccccc}
\hline $\begin{array}{c}\text { Code } \\
\text { number }\end{array}$ & $\begin{array}{c}\text { Age } \\
\text { years }\end{array}$ & Color & $\begin{array}{c}\text { Socio-economic } \\
\text { status (A to E) }^{\mathbf{a}}\end{array}$ & STDs & $\begin{array}{c}\text { HHV-8 IFA-LANA } \\
\text { Ab titer }\end{array}$ & $\begin{array}{c}\text { HHV-8 IFA-Lytic } \\
\text { Ab titer }\end{array}$ \\
\hline 1 & 21 & P & C & Yes & 100 & - \\
2 & 32 & W & E & Yes & - & 100 \\
3 & 60 & W & D & Yes & 50 & - \\
4 & 49 & W & D & Yes & 100 & 800 \\
5 & 31 & W & D & No & 100 & - \\
$6^{\mathbf{b}}$ & 21 & B & D & Yes & 100 & 100 \\
$7^{\text {c }}$ & 51 & B & E & Yes & - & - \\
\hline
\end{tabular}

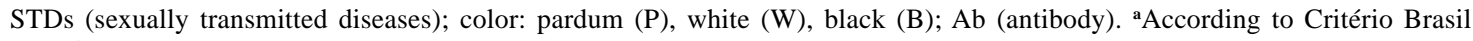
[17]; ' HIV-seropositive, 'KS-AIDS case.

In addition, if we compare the results obtained just in the HIV-1-infected female CSW, 1 out of 6 HIV-1-infected cases resulted HHV-8 seropositive (16.7\%) (Table 1). Again, despite of the high prevalence of $16.7 \%$, this result is under the prevalence rates detected among homosexual/bisexual men from São Paulo (30.4-34\%) (Table 1).

Another interesting data that emerged from this study was the strong association of HHV-8 seropositivity and the age: in spite of the fact that most of female CSW belong to the age group of 18-30 years (71\%), 4 out of 6 that resulted HHV8 seropositive, were more than 31 years old (Table 2). Concerning the color, 77 out of 90 women were white, but HHV-8 antibodies were detected mostly among black (1 out of 4 cases), and among pardum women (2 out of 9 cases). We do not know if HHV-8 infection was associated with the ethnic background of women or whether it reflects the deficient socioeconomic and educational conditions of these women. In addition, 5 out of 6 HHV-8-seropositive women disclosed history of STDs (Table 2). The STDs could be considered a marker of promiscuity rather than a specific co-factor of HHV8 infection. In a number of countries, HHV-8 seroprevalence in prostitutes has being higher than in non-prostitutes women, suggesting that the former are a high-risk population [14].
An increase in HHV-8 seroprevalence with age suggests that, new infection occurs during adulthood [18], and this finding was also detected in Brazil [2,5].

It is interesting to point out that in one black woman, aged 51 years, and of whom KS was diagnosed previously as the first manifestation of AIDS, no HHV-8 antibody was detected. We attribute the HHV-8-seronegative result to the impaired immune response of patient, since she presented several opportunistic infections at the time of blood collection, but no KS lesions.

Whether STDs provide HHV-8 transmission or are markers of shared high-risk behavior cannot be determined by a crosssectional study design.

Length of time in the practice of prostitution, licit and illicit drug use, sex acts, number of sex partners per day, all these variables were investigated in the present study, but none of them showed correlation with HHV-8 seropositivity. An interesting point that emerged from this project was the detection of HHV-8 anti-latent antibodies in prostitutes of this geographic region, and this finding prompts us to investigate the prevalence of HHV-8 antibodies in referent female population from the same area. Indeed, because Imbituba is a port city that receives ships from all parts of the 
world and also is spread out along the BR 101 highway, this city could be portal of entry and a dissemination place of STDs to the rest of Brazil and others Latin America countries, as well as to the rest of the world. Of note, in this population, HIV-1 genotype $C$ was identified in the majority of cases, in spite of the prevalence of genotype B in Brazil [16].

\section{References}

1. Hengge U. R., Ruzicka T., Tyring S. K., et al. Update on Kaposi's sarcoma and other HHV-8 associated diseases. Part 1. epidemiology, environmental predispositions, clinical manifestations, and therapy. Lancet Infect Dis 2002;2:281-92.

2. Biggar R.J., Whitby D., Marshall V., et al. Human herpesvirus 8 in Brazilian amerindians: A hyperendemic population with a new subtype. J Infect Dis 2000;181:1562-8.

3. Caterino-de-Araujo A., Calabrò M.L., Santos-Fortuna E., et al. Searching for HHV-8 antibodies in serum samples from patients infected with HIV1 and blood donors from São Paulo, Brazil. J Infect Dis 1999;179:1591-2.

4. Caterino-de-Araujo A., Carbone P.H.L, Martinelli F.L.B, et al. Absence of an association between the presence of human herpesvirus 8 antibodies and the development of Kaposi's sarcoma in HIV-1-infected patients receiving anti-retroviral therapy. AIDS 2000;14:1-2.

5. Cunha A.M.G., Caterino-de-Araujo A., Costa S.C.B., et al. Increasing seroprevalence of Human herpesvirus 8 (HHV-8) with age confirms HHV-8 endemicity in Amazon Amerindians from Brazil. J Gen Virol 2005;86(9):2433-7.

6. Souza, V.A., Sumita L.M., Freire W., et al. Prevalence of antibodies to human herpesvirus-8 in populations with and without risk for infection in São Paulo State. Brazilian J Med Biol Res 2004;37:123-7.

7. Zago A., Bourboulia D., Viana M.C., et al. Seroprevalence of human herpesvirus 8 and its association with Kaposi's sarcoma in Brazil. Sex Transm Dis 2000;27:468-72.
8. Zhang X.-Q., Fitzpatrick L., Campbell T.B., et al. Comparison of the prevalence of antibodies to human herpesvirus 8 (Kaposi's sarcoma-associated herpesvirus) in Brazil and Colorado. J Infect Dis 1998; $178: 1488-91$.

9. Chang Y., Cesarman E., Pessin M.S., et al. Identification of herpesvirus like DNA sequences in AIDS-associated Kaposi's sarcoma. Science 1994;266:1865-9.

10. Peterman T.A., Jaffe H.W., Beral V. Epidemiology clues to the etiology of Kaposis's sarcoma. AIDS 1993;7:60511 .

11. Serraino D., Franceschi S., Dal Maso L., La Vecchia C. HIV transmission and Kaposi's sarcoma among European women. AIDS 1995;9:971-3.

12. Caterino-de-Araujo A., Santos-Fortuna E., Carbone P.H.L., et al. Human herpesvirus 8 (HHV-8) antibodies among women from São Paulo, Brazil. Association with behavioral factors and Kaposi's sarcoma. Brazilian J Infect Dis 2003;7:395401.

13. Kedes D.H., Ganem D., Ameli N., et al. The prevalence of serum antibody to human herpesvirus 8 (Kaposi sarcoma-associated herpesvirus) among HIV-seropositive and high-risk HIVseronegative women. JAMA 1997;277:478-81.

14. Bestetti G., Renom G., Mauclére P., et al. High seroprevalence of human herpesvirus-8 in pregnant women and prostitutes from Cameroon. AIDS 1998;12:541-3.

15. Enbom M., Tolfvenstam T., Ghebrekidan H., et al. Seroprevalence of human herpes virus 8 in different Eritrean population groups. J Clin Virol 1999;14:167-72.

16. Trevisol F.S. Master thesis. Universidade do Sul de Santa Catarina, Tubarão. Inquérito soroepidemiológico para HIV em mulheres, profissionais do sexo, em Imbituba - SC. 2004.

17. Critério de Classificação Socioeconômica Brasil. [Online] http:// www.somatorio.com/criteriobrasil.asp. Accessed 16 December 2003.

18. Lavreys L., Chohan B., Ashley R., et al. Human herpesvirus 8: Seroprevalence and correlates in prostitutes in Mombasa, Kenya. J Infect Dis 2003;187:359-63. 